Pelham WE, Stein MA et al. Validity of DSM-IV attention-deficit/hyperactivity disorder for younger children. I Am Acad Child Adolesc Psychiatry July 1998;37:695-702). (Reprints: Dr Lahey, Department of Psychiatry (MC 3077), University of Chicago, 5841 South Maryland Ave, Chicago, IL 60637).

COMMENT. DSM-IV criteria for subtypes of ADHD are valid in younger children, aged 4 through 6 years. All children diagnosed with ADHD showed significant functional impairments in behavior, attention, and social skills, and deficits in academic achievement.

\title{
NEUROBEHAVIORAL OUTCOME IN CRANIOPHARYNGIOMA
}

The records of 20 children with craniopharyngioma seen between 1983 and 1995 were reviewed at the University of Colorado Health Sciences Center, Children's Hospital, and the Denver VA Medical Center, CO. Post-surgical social behavior and school performance were assessed by neuropsychological tests and standardized rating scales over a mean follow-up period of 38 months. Moderate or severe impairment of neurobehavior occurred in $12(60 \%)$, and only 3 had a good outcome. The outcome was independent of partial or gross total resection of the tumor. The possible adverse effects of radiation therapy used in $17(85 \%)$ could not be evaluated, but the age at the time of irradiation and the degree of dysfunction were not related. The common feature of the tumors was location in diencephalic and adjacent limbic regions, and the direct involvement of these structures appeared to correlate with neurobehavioral impairments. (Anderson CA, Wilkening GN, Filley CM, Reardon MS, Kleinschmidt-DeMasters BK. Neurobehavioral outcome in pediatric craniopharyngioma. Pediatr Neurosurg May 1997;26:255-260). (Respond: C Alan Anderson MD, Department of Neurology, University of Colorado Health Sciences Ctr, Denver, CO).

COMMENT. Behavioral assessments in addition to psychological testing are important in the pre- and post-surgical and -irradiation treatment of craniopharyngioma. The cognitive effects of cranial irradiation in children with acute lymphoblastic leukemia are reviewed in Progress in Pediatric Neurology III, PNB Publishers, 1997;pp424-6).

\section{DEGENERATIVE DISEASES}

\section{JUVENILE FAMILIAL AMYOTROPHIC LATERAL SCLEROSIS}

Four cases of JFALS in a family, with mean age at onset of 15.7 years and exceptionally long survival (mean, 27 years), are reported from the National Institute of Neurology and Neurosurgery, Mexico City. The father developed the classic form of ALS at 63 and died 2 years later. Three of the children had severe, and one moderate, dementia in adulthood. Cognitive deterioration began a few years after onset. MRI in one patient showed severe atrophy of cortex and brain stem, but the classic pyramidal degeneration was slight. (Siliceo EO, ArriadaMendicoa N, Balderrama J. Juvenile familial amyotrophic lateral sclerosis: four cases with long survival. Dev Med Child Neurol June 1998;40:425-428). (Respond: EO Siliceo MD, Torcuato Tasso 335-401, Chapultepec Morales 11570, Mexico DF, Mexico).

COMMENT. A juvenile form of familial ALS has an onset in late childhood and a long survival, complicated by dementia. Genetic analysis in FALS show 20\% linked to chromosome 21q21, and the remaining $80 \%$ unidentified (Siddique T et al. Neurology 1996;47 (Suppl 2):27-35). 